\title{
A Fall from Grace: An Interpretative Phenomenological Analysis of Unemployment in UK University Graduates with Common Mental Health Issues
}

\author{
Christopher J. Cockshott ${ }^{*}$, Gundi Kiemle², Paula Byrne ${ }^{3}$, Mark B. Gabbay ${ }^{2}$ \\ ${ }^{1}$ Department of Psychology, Faculty of Education, Health and Wellbeing, University of Wolverhampton, \\ Wolverhampton, UK \\ ${ }^{2}$ Department of Primary Care and Mental Health, Liverpool, UK \\ ${ }^{3}$ Department of Public Health, Policy and Systems, Institute of Psychology, Health and Society, University of Liverpool, \\ Liverpool, UK \\ Email: ^C.Cockshott@wlv.ac.uk
}

How to cite this paper: Cockshott, C. J., Kiemle, G., Byrne, P., \& Gabbay, M. B. (2021). A Fall from Grace: An Interpretative Phenomenological Analysis of Unemployment in UK University Graduates with Common Mental Health Issues. Open Journal of Social Sciences, 9, 291-313.

https://doi.org/10.4236/jss.2021.91021

Received: December 17, 2020

Accepted: January 22, 2021

Published: January 25, 2021

Copyright $\odot 2021$ by author(s) and Scientific Research Publishing Inc. This work is licensed under the Creative Commons Attribution International License (CC BY 4.0).

http://creativecommons.org/licenses/by/4.0/

\begin{abstract}
An exploratory investigation into the experiences of unemployed university graduates with common mental health issues (i.e., depression and anxiety) was conducted using Interpretative Phenomenological Analysis. Analysis of semi-structured interviews with 12 graduates in their twenties, all of whom had been unemployed between five and 24 months with common mental health issues, generated themes relating to "Loss of Expectation and Disorientation", "Waste, Failure and Blame", and "Stigma and Shame". Participants had experienced a "Fall from Grace"-a descent from a vaunted position of high-esteem and importance as university graduates, with seemingly bright prospects for a privileged future, into a lowly state of unemployment with mental health issues, leaving them feeling tarnished. These findings are discussed in relation to the literature on graduate unemployment, crisis and stigma, raising some practical issues for universities, including counselling services, and how they can better manage the transition to employment for their graduates.
\end{abstract}

\section{Keywords}

University Graduate Unemployment, Graduate Expectations, Stigma and Shame, Common Metal Health Issues, Interpretative Phenomenological Analysis (IPA)

\section{Introduction}

Despite a strong national focus on the employability of university graduates in 
the UK and the considerable investment made by society in this group, they remain a particularly under-researched group. Little is known about their experiences once they leave university, as they attempt to carve out a career for themselves in a highly competitive graduate jobs market (Institute of Student Employers [ISE], 2020), which has been further intensified by the COVID-19 crisis, as graduate employers reduce their planned recruitment (ISE \& Association of Graduate Careers Advisory Services [AGCAS], 2020).

Unfortunately, substantial numbers of graduates do not simply "walk" straight into their preferred jobs and careers after leaving University. Many are forced into taking on roles outside of their intended career plans or they experience underemployment, perhaps undertaking some form of part-time or voluntary work (Jisc \& AGCAS, 2020). However, there are some university graduates who do not manage to find any employment at all and experience lengthy spells of unemployment (Jisc \& AGCAS, 2020). They fail to make the expected transition from university to work, and to compound their plight they also struggle with common mental health issues, such as depression and anxiety.

While there are no extant data on the prevalence of unemployed university graduates with common mental health issues, the numbers are likely to be worthy of public attention, given the high rates of common mental health issues in students attending FE and HE institutions (National Union of Students-Union of Students in Ireland [NUS-USI], 2017; Shiels, Gabbay, \& Exley, 2008), and in young adults in general (McManus et al., 2016). Moreover, there is strong evidence demonstrating the detrimental impact of unemployment on mental health (e.g., McKee-Ryan et al., 2005; Paul \& Moser, 2009), while mental health issues also restrict an individual's capacity and willingness to pursue opportunities to move into work (Dooley, Catalano, \& Brownell, 1986; Kasl, 1982; Olesen et al., 2013).

Given these concerns and the potential vulnerability of these graduates, it is surprising that there has been no research into their lived experiences, which therefore leaves many gaps in our knowledge of the struggles, fears and aspirations of this group. The present study therefore adopted an exploratory and qualitative approach that aimed to shed some light on the concerns, difficulties and challenges of these graduates during what must be a difficult period in their lives. The use of Interpretative Phenomenological Analysis (IPA) (Smith, 1996; Smith, Flowers, \& Osborn, 1997) was well-suited to this purpose, as it enabled the indepth exploration of graduates' sense-making and shared understandings of their unemployment and common mental health issues.

\section{How Well Do University Graduates Cope with Unemployment? A Review of the Quantitative Literature}

There is a paucity of evidence and no continuity of research into the impact of unemployment on university graduates' mental health. The protective benefits of being a graduate are thought to include the absence of an established occupa- 
tional identity, the recent experience of lengthy leisure time as students (Hayes \& Nutman, 1981), as well as having the achievement of being a university graduate, which might help to maintain high levels of self-esteem that is demonstrated in well-educated and highly qualified individuals (Pukey, 1970). Although the disparity between graduates' high expectations relating to occupational identity and the corresponding loss in social status associated with unemployment might be an aggravating factor (Bakke, 1940).

Of the few empirical studies in the area, those that report unemployment to have a detrimental effect on the psychological health of recent graduates (i.e., Cassidy \& Wright, 2008; Feather \& Bond, 1983) seem to conflict with those suggesting that unemployment does not necessarily lead to psychological distress (Cassidy, 1994; Lacković-Grgin et al., 1996; Schaufeli \& Van Yperen, 1992). Moreover, levels of distress may decrease over time in recently unemployed graduates (Schaufeli \& Van Yperen, 1992).

These apparent discrepancies, however, may be reconciled by considering a range of other factors that impact on this relationship. For example, LackovićGrgin et al., (1996) and Schaufeli and Van Yperen (1992) consider the economic and cultural context of their respective countries (Croatia and Netherlands) as a means of explaining their findings. For example, a poor economic outlook might have led participants to ascribe their unemployment to these systemic problems, rather than personal factors (Lacković-Grgin et al., 1996). In addition, low expectations of employment, especially in degree subjects that are associated with high-levels of unemployment, may also be an important factor in buffering the impact of unemployment (Lacković-Grgin et al., 1996).

The role of social norms (e.g., normalisation of unemployment and changing female work-role attitudes in society) are also considered to impact on how graduates view their unemployment (Lacković-Grgin et al., 1996; Schaufeli \& Van Yperen, 1992). Similarly, a more detailed examination of the nature of employment in Cassidy and Wright's (2008) UK study, which also focuses on underemployment (i.e., working in jobs below one's skill level) is also an important consideration. Their findings that underemployment is often more detrimental than unemployment to the psychological health of graduates suggests that employment that does not meet their expectations or aspirations may be more psychologically distressing in the short-term than being unemployed with an optimistic outlook. This explanation might therefore account for Cassidy's (1994) conflicting findings that unemployed graduates in the UK did not experience significantly greater psychological distress than their employed counterparts.

Other factors that are important considerations in how graduates cope with unemployment were highlighted by Feather and Bond's (1983) Australian study, who found that unemployed graduates had more depressive symptoms and were less organised and purposeful with their time than their employed counterparts. However, the cross-sectional design of their research meant that it was not possible to elucidate if poor use of time was a precursor to unemployment and de- 
pressive symptoms, or a reflection of these.

\subsection{Qualitative Research on Graduate Unemployment}

In a qualitative examination of graduates' transition from university to unemployment in Canada, Borgen, Hatch, and Amundson's (1990) found that the initial optimism and high hopes upon graduation correspond with Burke and Macdermid's (1999) findings relating to the hopeful outlook of business school graduates in Canada regarding career and economic prospects. Interestingly, Borgen, Hatch, and Amundson (1990) report that it may take up to 3.5 months before a "downward trend" of gloom and pessimism (sometimes depression) of post-graduation unemployment sets in. However, the variation in the length of this "vacation period", estimated to be between 3 weeks to 3.5 months, suggests that the protective benefits of being a graduate on outlook and mental health is largely due to the experience of "positive" incidents (e.g., job interviews and social support), which mitigate the detrimental effects of "negative" incidents (e.g., unsuccessful job search, poor work/job opportunities, lack of social support, self-doubt or guilt and stagnation or boredom).

\subsection{Modern-Day UK Higher Education and Graduates}

While the research described above provides important insight into the potentially detrimental impact that unemployment has on the psychological health and well-being of graduates, these studies are mostly from the 1980s/90s, with Cassidy and Wright's (2008) UK study being the most recent. UK higher education has undergone huge changes since this time, with the move from an "elite" to a "mass" system of widening participation in the early 1990s, the introduction of tuition fees in England in 1998 and the corresponding increase in student debt, and an increasingly neoliberal and marketised system of higher education centred around student employability.

\subsection{The Aims and Approach of the Present Study}

Given the considerations described above, the present study aimed to update and build on the extant literature by investigating the lived experiences of a small group of recently unemployed UK university graduates who have common mental health issues. IPA (Smith, Flowers, \& Larkin, 2009) was well-suited for this purpose, as it is an approach that is rooted in psychology and specifically tailored to examining specific instances of experience, particularly those relating to major life experiences and transitions (Brocki \& Wearden, 2006), such as unemployment and mental health issues.

IPA blends together phenomenological, hermeneutic and idiographic tenets into a distinct methodological mode of enquiry towards conducting qualitative psychological research. By adopting this approach, the researchers were able to prioritise participants' unique voices in terms of their explanatory importance. This meant being receptive to the diversity of participants' understandings of the 
world (Smith, 2004), which were examined in terms of perceptions and meanings (whether idiosyncratically or socially constructed), with the purpose of providing an integrated and conceptual account that was shaped by an ongoing process of subjective interpretation and construction (Smith, Flowers, \& Larkin, 2009). Because of this focus on subjective meaning, the research question focused on how these graduates experienced and made sense of their unemployment and mental ill health.

\section{Method}

\subsection{Design and Participant Recruitment}

This was a qualitative study using Interpretative Phenomenological Analysis (Smith, Flowers, \& Larkin, 2009). Participants were selected using purposive homogeneous sampling (Smith, Flowers, \& Larkin, 2009) and were recruited using social media and networking sites (e.g., student/graduate employment and mental health websites, forums and blogs).

\subsection{Sample}

Twelve university graduates (nine females and three males) between the ages of 22 and 28 took part; all graduating between 2008 and 2012 with their Bachelor's degrees in a variety of subject areas, including: Arts, Humanities, Social Science, Education and Science. Participants had been unemployed between five and 24 months in duration, although nine of the participants had prior employment experience since graduation, including temporary, part-time or voluntary positions for which they did not need a degree.

Participants self-represented as having been diagnosed between 2001 and 2012 with mental health issue(s) that were deemed to be "common" (McManus et al., 2009; National Institute of Health and Clinical Excellence [NICE], 2011), and comprised: Depression, anxiety, generalised anxiety, panic attacks and obsessivecompulsive disorder. The onset of these mental health issues pre-dated their unemployment in all but one participant (Paula) and all participants were in receipt of medical and/or psychological treatment at the time of the study (see Table 1 below for a more detailed breakdown of participants' characteristics).

Individuals were excluded from participating in the study if they also were diagnosed with severe mental health issues (e.g., psychosis and/or bipolar disorder), had a physical health condition(s) and/or severe or problematic substance dependency/abuse difficulties. Any of these issues were considered to reduce the homogeneity of the sample by potentially altering their experience of being unemployed with common mental health issues.

\subsection{Interview Guide Development}

IPA's approach to data collection is based on the convention of using a semistructured interview guide (Smith et al., 2009), and this format was used in the current study. Draft versions of topic areas, questions, and their prompts were 
Table 1. Participants' biographical details.

\begin{tabular}{ccccl}
\hline Participant & Age & Ethnicity & $\begin{array}{c}\text { Length of } \\
\text { Unemployment } \\
\text { (months) }\end{array}$ & \multicolumn{1}{c}{ Diagnosis of Mental Health Issues } \\
\hline Kate & 27 & White/British & 5 & Depression and generalised anxiety (2003) \\
Laura & 26 & White/British & 24 & Anxiety (2005); depression (2001) \\
Jessica & 23 & White/British & 5 & Depression and anxiety (2008); binge eating (2010) \\
Alison & 25 & White/British & 24 & Anxiety and panic attacks (2010) \\
Sophie & 22 & White/British & 7 & Generalised anxiety (2008); depression (2010) \\
Elizabeth & 25 & White/British & 5 & Depression (2009); generalised anxiety (2010) \\
Louise & 26 & White/British & 9 & Panic attacks, anxiety and OCD (2005) \\
Rebecca & 23 & White/British & 8 & Depression and anxiety (2012) \\
Paula & 25 & Middle Eastern/British & 7 & Anxiety (2010) \\
Mark & 27 & White/British & 21 & Depression, anxiety and panic attacks (2012) \\
Fabio & 25 & Latin American/British & 17 & Depression and anxiety (2010) \\
Paul & 28 & White/British & 17 & Depression (2005) \\
\hline
\end{tabular}

${ }^{\star}$ Pseudonyms are used.

discussed in order to judge their suitability, coherence, and comprehensibility. Questions inquired into their sense-making of being unemployed with mental health issues in relation to how they thought or felt about themselves, as well as their feelings towards work/employment and their careers. Prompts were also used if needed and these clarified the type of questions that were being asked. Prompts were also designed to help participants answer the questions by providing more concrete examples to clarify the sorts of questions that were being asked.

\subsection{Data-Collection and Analysis}

Semi-structured interviews were conducted with the 12 participants, which were audio-recorded with participants' permission and lasted between 45 and 80 minutes. All interviews were transcribed verbatim and analysed by the first author in accordance with Smith, Flowers, and Larkin's (2009) indicative steps for IPA. This process began with data familiarisation by reading through each participant's transcript several times, recording initial thoughts about its content and meaning. This was followed by a line-by-line analysis using descriptive, conceptual and linguistic noting, which drew out the underlying phenomenological content before adding a more conceptual account based on the first author's interpreted understanding of the participant's experience.

This body of initial notes was then organised into a conceptual structure of emergent themes that fittingly summarised the phenomenon at hand. These emergent themes were further examined for how well they converged or diverged from each other, which enabled them to be clustered into higher order 
super-ordinate or overarching themes, which captured the most significant and important features of the participant's experience. The final stage of the analysis involved cross-referencing these themes for each participant, searching for patterns, connections and discrepancies, so that they could be clustered into themes for the group. These themes represented a higher-order conceptual rendering of the most significant and important features of the group's experiences.

At each stage of the analysis the first author discussed his findings with the research team, testing his interpretations against different potential viewpoints, which enhanced the credibility of the analytic process. A further check to enhance the rigour of the analysis involved assessing the prevalence (recurrence) of all themes across the group. This revealed that all themes were strongly represented in participants with only Jessica's account omitting the sub-theme of Waste, Failure and Blame, as she did not raise these issues in her interview.

\section{Findings}

\subsection{Fall from Grace}

The theme "Fall from Grace" related to participants' perceived loss of status, prestige and respect as university graduates by becoming unemployed. The title of the theme refers to the idiomatic expression that is also closely associated with the Christian biblical story of the expulsion of Adam and Eve from the Garden of Eden for their disobedience to God. Participants similarly experienced a metaphoric fall from grace. They had undergone a major transition in their lives: from a vaunted and lofty position of high-esteem, rank and importance as university graduates, with seemingly bright prospects for a privileged future, they experienced a dramatic descent into a lowly state of unemployment with mental health issues. Participants' response to this "fall" and the meanings that they ascribed to it were organised around three constituent sub-themes: 1) Loss of Expectation and Disorientation, 2) Waste, Failure and Blame, and 3) Stigma and Shame, which are explored below.

\subsubsection{Loss of Expectation and Disorientation}

Upon graduation, participants were in buoyant spirits and harboured a strong sense of success that imbued them with confidence. This was accompanied by a sense of strong optimism for their future and employment prospects. They felt a sense of omnipotence and of having "the world at [their] feet", as they eagerly anticipated the tremendous range of high-flying opportunities that they presumed were awaiting them. They felt in command of their own destiny and believed they were capable of pursuing any career that they pleased:

I felt like I had the world at my feet when I was a graduate. I felt that I was gonna walk straight into this amazing career job .... So, I was gonna be fighting them off with a stick, you know, that's what I was told, er .... [Louise]

I thought I would get my degree and start working straight away, but it 
hasn't turned out like that. [Paula]

Their high spirits, confidence and optimism towards their future even trumped the negative constraints imposed upon them by their mental health issues. They considered themselves to be no different to their peers in all respects and seemed to disregard their mental health as a potential hindrance to their chances of securing employment after university:

I think like anyone else, you think you're gonna get a job. It's nothing to do with mental health or anything like that. You think there's gonna be a job out there .... [Kate]

In stark contrast to these feelings, participants described unemployed life after graduation to be radically different to what they thought it would be like prior to graduation. They were hugely disappointed with the direction that their lives had taken since graduation, having failed to meet any of their high expectations relating to their careers and what they thought they would be able to achieve with their degrees:

It hasn't been anything like I expected it to be. Er ... what I imagined would happen was that I'd find a place on, like, I wasn't expecting a massively well-paid job, but I was expecting something where I'd be comfortable and I'd be earning more than when I started and that wasn't the case at all. [Mark]

I've never not worked or not studied so ... and now I don't do either. I didn't expect this to happen. [Laura]

Some participants described the moment of realisation that their hopes and expectations were in vain as a flat and empty end to their student years, which left them feeling deflated. Their seemingly sullen feelings towards their own circumstances were in stark contrast to the joy of their peers and friends, who had reason to rejoice:

Basically, it [post-university] wasn't as exciting and uplifting as I thought it would be. Everyone else was celebrating and it was nothing for me. [Jessica]

For other participants, the realisation that their hopes and expectations had failed to materialise post-university was experienced as a surprise that left them seemingly stunned with disbelief and vulnerable to a deterioration in their mental health:

It [post-university] seemed a bit of a shock. I'd been applying for jobs while I was still at university, so I knew it was tough. I knew there was a lot of competition around, but I still assumed I'd find something fairly quickly, and when it didn't turn out that way that's when I started to feel depressed again. [Paul]

Participants struggled to come to terms with their unemployment. Their "shock" and disbelief related, in part, to their high expectations and sense of invulner- 
ability that unemployment was something that would and should not have happened to them. They held such a strongly optimistic outlook towards their lives prior to graduation that they felt an inevitability that they would obtain suitable employment, as if it was predestined to happen to them just as much as it was for their peers and friends:

Everyone was just starting posts and jobs and stuff, and I just, I dunno, I just keep quiet, it kinda upset me because it was meant to happen to me as everyone else. [Sophie]

The sudden manner in which their entire career and life plans were disrupted was experienced dramatically, as if they were cast into the air and thrown into disorder, leaving participants feeling disorientated and confused. They lost their poise and balance, as they struggled to regather themselves by finding their bearings, leaving them feeling a great deal of uncertainty towards themselves and their circumstances:

... the whole rug has been pulled from under me at the moment. [Louise]

Participants expressed the enormous negative impact of their unemployment in terms of how they thought and felt about themselves. For example, the combined effect of being unemployed with mental health issues was experienced as a double assault on their dignity and sense of pride. They viewed unemployment as one of the worst things that could have happened to them at a time when they were already weak and vulnerable because of their ongoing mental health issues. Participants believed that they would have fared better, especially in terms of their mental health, if they had made a seamless transition from university into employment, rather than experiencing unemployment immediately after graduation:

Yes, I felt like it's been another kick in the teeth and I wasn't feeling happy anyway ... and it's knocked me while I was down ... the last thing I needed after graduating. [Paul]

Yes, um ... I don't think I would have probably suffered it so much if I wasn't unemployed. I think if I'd had quite a smooth transition from university and got the job I wanted, it probably would be different and I wouldn't have suffered with it. [Paula]

Their lives seemed to have been turned upside down and taken away from them; they had not only lost what they had worked for, but also what they did not yet have and strongly hoped or expected would be-a career and the start of a new life as adults:

Being unemployed you haven't, all you've done is lose, it's like the complete opposite, you start off up here and then you end up ... you just feel like you've lost everything ... [Louise]

Participants had effectively left university only to find themselves to have en- 
tered a "desert", which indicated the disorientating change in landscape, as they were now confronted with a very different and less forgiving terrain. It represented a harsh economic climate-barren, lifeless and desolate of opportunityand their almost hopeless struggle to succeed in the highly competitive environment of the graduate jobs market:

I just felt, right, I felt like I literally just opened the door and walked into a desert, just, just nothing there, and ... yeah that's where things started to become more difficult, I found. [Fabio]

For some participants, the wilderness of their unemployment and lack of purpose was also reflected in their sense of an incomplete self and identity. Their unemployment represented a "void" or nothingness, which was felt as an emptiness or absence of graduate identity, as there was nothing to replace it, leaving them with a huge space to fill. In this sense, being unemployed was a non-identity or an anonymous sense of self as unknown:

... it [unemployment] did create the lack of purpose, the void of identity I suppose, my identity as a graduate who was progressing in the world ... just gone and there wasn't any scope for progression, I couldn't see where I was going then. [Elizabeth]

Other participants, by contrast, expressed feeling a more nebulous sense of self, which was perhaps an indication of their disorientation in relation to their circumstances. They were altogether unsure of the impact that being unemployed with mental health issues had on how they saw themselves, although some now thought more deeply and seriously about themselves because of their circumstances:

Er ... I think it's just made me question my identity more ... I don't know if it's changed it. [Rebecca]

Er, I don't know. I've always been quite a cautious person that tended to get stressed out, but ... er, I don't know, I just find it harder to cope with little things now .... [Alison]

\subsubsection{Waste, Failure and Blame}

Participants' unemployment left them feeling fallible and subject to reproachthe very opposite to their feelings of success prior to their unemployment. The constituent theme of "Waste, Failure and Blame" related to participants' sense of waste and failure because of their unemployment and the questioning of themselves, including the role of their own actions and responsibility for their circumstances. Their self-worth was left undermined and was accompanied by feelings of deep unhappiness and anger towards themselves.

Their value as university graduates, who originally harboured high expectations and ambitions of using their degrees to pursue a career that fulfilled their aspirations, was drastically diminished by their unemployment. They not only felt an enormous sense of unnecessary waste, but a humiliation as their dreams, 
hopes, skills and abilities-what they had to offer the world-were seemingly unwanted and disposable, to be washed away "down the drain" as unimportant and forgotten about:

Because of being a graduate and you know the, the, I need to be working to actually use some skills and fulfil my own expectations of myself. ... so your feelings of self-worth just go down the drain. [Elizabeth]

Their sense of waste related to their feelings of being useless and unproductive, as they were unable to make a positive contribution, which meant that they lacked a meaningful and significant purpose in life. They were wasting their potential, and this reinforced their pre-existing feelings of inadequacy from having mental health issues. The combination of the two often led them to feel a sense of futility, as they expressed bleak and self-pitying sentiments, and in some cases, to question the value of their existence:

I don't think, like, in terms of what I do with my life, what I can do with my life, at the moment I feel like I'm wasting it, like it's worthless, there's no point me being here. It gets like that a lot ... just makes me feel really shit about myself. [Sophie]

Participants also struggled with feelings of guilt, as if they were punishing themselves for their failure, by believing that they had become a burden on others and on society in general. They felt "worse than worthless" and so instead of adding something of value (positive) to society, they had become a drain (negative) - of having a value less than zero-by using up precious resources and taking them away from others, as if they did not deserve to exist:

I'm worse than worthless because I'm taking up other people's energy etc. I'm just using up oxygen and space and government money, and all the rest of it, I'm not worth it. [Laura]

Participants' misery and sense of failure towards their circumstances was magnified by their comparisons with their peers or friends, who had gone on to succeed by finding suitable employment. They were especially drawn towards the material acquisitions of their friends that stemmed from having jobs and money, which served only to make them feel worse by reminding them of their own dire material and financial circumstances. Participants felt as if they had lost out, as in a game where success was gauged in material terms:

... I feel like I've failed. I think I'm the only person out of a class of seventy who didn't get a job. [Sophie]

You don't have any money for a car, you don't have anything that your peers have, you just feel like a failure ... I felt like a loser, a total loser ... [Paula]

Participants reflected on the value of their decision to go to university and felt a great deal of regret with their choice, given their unemployment and the debts 
they had incurred. They felt a sense of wasted effort and resources that had been spent uselessly and to no avail, as they were seemingly no better off than before they went to university. They had been cast into a barren and desolate wasteland or "desert" described earlier, bereft of fruitful material reward for their hard work, left with nothing but a bleak outlook of being able to cultivate viable employment opportunities for their future:

... As I said before, I feel like it's been a massive waste of time and money like ... I think I'm 34, 35 grand in debt with student loans and I've got nothing to show for it ... there was no point doing it. [Kate]

I feel I've like put so much effort in with my uni work, I'd like to do something that will build on those skills that took time to develop, rather than bar work, which I could have done three years ago. [Rebecca]

Some participants felt a strong sense of injustice towards their unemployment, as if they had been cheated. Rather than this sense of unfairness stemming from their feelings of having a right or entitlement-implying guaranteed access-to jobs that they had been denied, participants instead felt that they had a legitimate claim to suitable jobs based on their qualifications, experience and hard work. They felt that they were worthy of suitable employment and deserved a fairer, better outcome based on their own merit. They had worked hard at school and university in good faith and this had been left unrewarded:

I feel like it's not fair. I feel like I work really hard at school and uni to carve a life out for myself and I've just ended up here stuck on benefits, it's just not fair. [Louise]

This retrospective examination of the decisions that they had made served to bring their unresolved mental health issues into sharper focus by prompting them to take stock of these. This often compounded their misery, as their issues remained unresolved and troublesome to them:

I think well I shouldn't have tried going back to university to do another degree because it hasn't got me anywhere. I haven't shaken off my mental health problems and used up all that time and spent all that money. [Paul]

Their mental health issues were inextricably bound-up with this self-examination and played a significant role in shaping their feelings of responsibility for their unemployment. For some participants, the integral role played by their mental health issues in their unemployment entailed a further retrospective examination of their management of these. This led them to often castigate themselves for not taking earlier and more decisive action to tackle their underlying issues, which seemed to be an indirect admission of responsibility for their unemployment:

I feel responsible [for his unemployment] more in the sense that I should have dealt with it [his mental health issues] earlier, maybe at a younger age, maybe when I was 14 and I realised I was feeling things that maybe a 14 year-old boy shouldn't do ... or maybe it's not the average sort of feelings 
that I should have and I thought I should have said something and dealt with it so when it would happen again in the future, I'd have a better grasp of dealing with the situation. [Fabio]

Other participants claimed that their mental health issues led them to feel responsible for their unemployment, believing their difficulties to be a punishment or vengeance for past misdeeds because there was something inherently bad or sinful about them. This sense of guilt and self-blame is explored further below in the next constituent theme entitled Stigma and Shame:

Mental health makes you feel like it's [her unemployment] your own fault and that you've brought it on yourself in some way and you deserve it .... I just used to rack my brains thinking I must be just a terrible person when all this stuff's happening to me. [Louise]

\subsubsection{Stigma and Shame}

The tensions between expectations of being a graduate and the lived experience of unemployment post-graduation, also engendered prejudicial attitudes, stigma and criticism. Participants referred to this stigma throughout their accounts, indicating that there was something disgraceful or shameful about being unemployed with mental health issues, which left them feeling marked or tarnished. They felt they had been labelled with generalised negative stereotypes of the unemployed, such as being parasitic, lazy, dishonest and undeserving:

Doley, benefit cheat, er, you know lazy good for nothing, sponging off our taxes, all of that .... [Laura]

Participants were deeply uncomfortable with these pejorative terms, which were incongruent with their identity as university graduates. They considered this prejudice to be wholly inaccurate, unjust and a misleading characterisation of themselves and their circumstances. They felt that they had wrongly and undeservedly become unemployed, as if it was an accident or a terrible mistake. Their proud status as university graduates, which they wore like a badge of honour, conferred on them an elevated social and economic rank that made them feel unworthy of their current lowly status. They felt a great sense of injustice as they felt degraded or demoted in rank or status, sometimes comparing themselves to socio-economic groups that they regarded to be beneath them. Their unemployment therefore left them with a sense of lost pride and challenged their dignity and intelligence as university graduates:

I felt that, the big difference really is pride, I suppose. I had something really to be proud of when I graduated. ... I just get made to feel like a cretin, er, you know, like a lower-class person, that's how it all makes you feel. [Louise]

There's like a stereotype around [her home town] anyway of the chavvy drug addict population [laughs] having to be on benefits and I'm not, I'm a university 
graduate who's just mentally ill. I can't get a job. It's not good, feel like I've been put in the wrong category. [Sophie]

I'm not choosing to be unemployed, you know. [Alison]

They also felt embarrassment, and even shame, for being unemployed, often trying to avoid admitting to others that they were out of work. They prevaricated or put a positive spin on it by rationalising it in one way or another to mitigate the extent to which others perceived them to be responsible for their circumstances. Participants' responses were indicative of the guilt that they felt for being unemployed. They clearly had a sense that they were doing something wrong by being unemployed and that they should be putting their lives to productive and meaningful use:

I just find the whole thing [her unemployment] very uncomfortable, especially when you meet people and they say 'what do you do for a living?' Oh my god, you bumble [starts mumbling] 'well you know, yes, blah, blah, blah, my degree's in this and I used to do this.' 'But you're not working at the moment?' 'Well, no.' The recession, that's what I'll blame, you know, it's just so uncomfortable. [Laura]

Yeah, I do brush over it, I don't want to tell people that I haven't been working for a period of time or whatever, so I just try and focus on the bigger things you know ... I did this, I did that, so sounds like I was actually doing something. [Paula]

Participants were especially concerned about the prejudice surrounding their mental health issues. While they were relatively sure that people would react negatively to their unemployment, they were less certain about the type of response that their mental health issues would receive. At one end of the spectrum, participants felt others might jump to the conclusion that they had very serious mental health issues, perhaps having lost contact with reality; or that they were feigning their difficulties and were simply "workshy" at the other end of the spectrum:

I think they [her fiancé's family] did think I was a bit ... they worried that either I was some insane mental person that was sitting in the corner rocking backwards and forwards that their son/brother was having to care for, or that I was kinda putting it on a bit and that I should really get back to work, that I was being lazy. I think they weren't sure where they sat.

[Louise]

Participants felt aggrieved and frustrated with the general ignorance and lack of empathy shown towards themselves and their mental health issues by others. They caricatured and satirised the crude understanding of mental health issues that they felt was common in society. They did so by typically highlighting the stereotyped view of an individual with mental health issues as blatantly crazy, whereas they understood their difficulties to be far more complex, subtle and 
multifaceted in nature:

Er, but other people, I don't really think they understand that they will only believe that you're mentally ill if you're wearing your pants on your head, a pencil up your nose saying wibble [laughs], that's it. ... there's a hell of a lot more going on behind someone's eyes than what, what might be apparent to most people. [Laura]

In contrast to a physical illness or disability, where its limiting effects on participants' capacity to work would be more readily understood, the invisibility of their mental health issues, along with their difficulty and struggle, remained hidden and unseen. This prevented others from readily apprehending the nature of their disability, leading participants to feel that they had to constantly defend themselves or persuade others of their difficulty and suffering:

... if I'd had an operation or I'd been in an accident, that support would have been there and it just wasn't, so I think with mental health you do feel like you have to get permission from people and kind of, you have to justify yourself, look I am really sick, look, look ... because it's invisible, I think. [Louise]

And then there's also the stigma that you get attached to being unemployed and claiming benefits ... a lot of people will turn round to you and go 'well, you know, why are you on benefits? There's nothing wrong with you.' ... they don't know anything about you, but you just mention it and they'll try and start an argument with you ... [Alison]

Participants similarly worried that others were doubtful of their reasons for not being at work, and that these would be seen as excuses that were not genuine or legitimate. They had to negotiate these blurred boundaries between being ill with mental health issues and appearing to be in good health at one and the same time. They were particularly concerned about being branded as lazy and emphasised that not being able to work because of poor mental health was categorically different to not making the effort to work. Participants seemed to therefore attach a strong stigma to laziness, as it implied they were to blame for their circumstances, something that they were exonerated from as they were poorly and simply unable to pursue any activity, despite their best wishes:

I don't know, sometimes I, I'm worried that people think I'm just trying to make excuses ... but I mean on my worst days I can't get out of bed, I don't even wash my hair, I don't want to wash myself, you know, nothing gets done. [Laura]

Some participants felt an added external pressure from others to obtain work simply by virtue of their status as university graduates who had degrees. They felt that there was a wide-spread belief that degree-level qualifications and skills automatically rendered them to be highly employable, enabling them to enter work without any difficulty. Once again, because their mental health issues were 
invisible and not readily apparent, others were less able to understand their full circumstances, often coming to the erroneous conclusion that laziness was the reason for their unemployment:

They see you as having a degree and having worked hard, it's like 'you're clearly clever enough, why aren't you working? You just must be lazy. [Jessica]

Participants clearly expressed their perception of the social unacceptability of mental health issues, and they were especially concerned about being discriminated against in a way that would hinder their chances of obtaining and maintaining employment. The uncertainty of how potential employers would respond to learning of their mental health issues lay beneath their dilemma to open up about them or to remain silent on the matter. However, their lengthening unemployment complicated the issue because of the gap in their CV that it created. This put them in the awkward and uncomfortable position of having to potentially disclose their mental health issues to prospective employers, which they were reluctant to do for the fear that they would be discriminated against:

... cos if I've got a CV that's completely empty after uni, the first thing they're [prospective employers] gonna say is, like "why didn't you work?" and it would be because of me mental health and so they'd want to talk about that and I'm not prepared to chat about that with them ... Are they [prospective employers] gonna take someone who has depression and high anxiety or are they gonna take the person who has got good people skills and who is a good orator and all stuff like that? I mean it's dead obvious, you know what I mean. No one, I mean, I wouldn't ever mention it until you'd been hired. [Sophie]

Participants were therefore strongly reluctant to divulge their mental health issues because of the stigma surrounding mental health in general. They went to great lengths to hide or disguise their difficulties from others, including their friends, as they wished to protect their reputation or public image. This pretence was indicative of the strong normative pressures operating on them to conceal their issues and the shame that they felt, but it was also a testament to their resilience and courage to try and carry on as normal, despite their difficulties:

Lots of people just think I'm normal, but just looking for a job, which in my own head, I feel really anxious and a lot worse than that, but I always try and, around other people, I'll never try and show that .... [Rebecca]

\section{Discussion}

The present study has offered a rich, interpreted description of the experiences of a diverse purposive sample of recently unemployed university graduates with common mental health issues. Unemployment for these graduates represented a major life-event for them, which had a substantial negative impact on how they 
thought and felt about themselves, as well as compounding their mental health issues.

Participants exhibited a multifaceted psychological response including shock and disorientation, accompanied by a strong sense of injustice, waste and failure. It had shattered their pre-graduation worldview of their sense of self as invulnerable, almost omnipotent, along with their corresponding high hopes, aspirations and expectations for their careers and personal lives in the future. They were left feeling tarnished and susceptible to criticism, prejudicial attitudes and stigma, as if they were to blame for doing something wrong by becoming unemployed with mental health issues.

\subsection{The Shock and Disorientation of Unemployment}

Participants' initial optimism leading up to graduation concurred with the findings of Borgen, Hatch, and Amundson (1990) and Burke and Macdermid (1999). However, this positive mindset associated with Borgen, Hatch, and Amundson's (1990) findings of a "vacation period" ended abruptly upon graduation, or shortly after, for participants, and the pessimism of the "downward trend" (Borgen, Hatch, \& Amundson, 1990) rapidly set in. They experienced the moment of first feeling unemployed as a sudden realisation-which typically came about through a comparison of themselves with peers and friends who had been successful finding work. This realisation left them with a sense of shock and disbelief or disorientation, as it was unexpected, and they felt it should not have happened to them. Although their mental health issues also contributed towards this negative reevaluation of their circumstances and sense of disorientation and pessimism, allowing the negative events to overshadow the positive achievements in their lives.

\subsection{A Disorientated Identity and Sense of Self}

Any potential protective benefits against unemployment that stemmed from an absence of occupational identity (Hayes \& Nutman, 1981) were un-felt as participants experienced a nebulous void connected to their unemployment. This was marked by a strong sense of uncertainty and ambiguity, which had a disorientating impact on their identity and sense of self.

According to the life-course development and crisis literature, the defining aspect of a crisis is disruption to the continuity of identity, which threatens the coherence of the sense of self (Becker, 1997; Levinson, 1978, 1996). Indeed participants felt overwhelmed and were immobilised by their circumstances during this uncertain time, which they struggled to comprehend (O'Connor \& Wolfe, 1987). Their integrity or "wholeness" was jeopardised and fragmented (Erikson, 1980) by their unemployment, challenging their sense of self, including their beliefs, expectations and self-worth, and was accompanied by the negative emotions of injustice, regret, failure, despair, as well as depression and anxiety (O'Connor \& Wolfe, 1987). A successful resolution to crises involves the realisation and acceptance of the need to adapt or change and pursue a new life direction (Hop- 
son \& Adams, 1976; Levinson, 1978, 1996; O’Connor \& Wolfe, 1987), a task that participants were struggling to resolve.

\subsection{Injustice or Inflated Sense of Entitlement?}

Students have been fed the narrative that getting a degree will guarantee them entry into high-paying and interesting jobs (careers), which for many (including those without mental health issues) has not been the case (Jisc \& AGCAS, 2020). Much has been written about Generation Y or the Millennials (Howe \& Strauss, 2000) (i.e., those born in the years ranging from the early 1980s to the early 2000s), and it is often asserted that this group have high expectations for their lives and hold a sense of being entitled (Twenge, 2006).

This was not the case for this group of graduates, who, despite being disadvantaged (and highly frustrated) from having mental health issues, believed that their high expectations and corresponding sense of injustice were not without foundation or some justification. They felt that they deserved or were worthy of a fairer outcome based on their own merit, which stemmed from a sense that they had a legitimate claim-rather than a right or entitlement-to suitable jobs based on their qualifications, experience and hard work.

\subsection{Stigma of being Unemployed with Mental Health Issues}

Participants' struggled with the discrepancy in their proud identity as university graduates and the stigmatising impact of being unemployed with mental health issues. They had found themselves involuntarily caught up and tarnished with the feckless and "undeserving poor" narrative, as if they had done something wrong by becoming unemployed with mental health issues. Thus, the achievement of being a university graduate, which might help to maintain high levels of self-esteem, as has been demonstrated in well-educated and highly qualified individuals (Pukey, 1970), only served to heighten participants' feelings of shame. In line with Bakke (1940), their high expectations relating to occupational identity and social status, meant that they experienced a greater loss of status, prestige and respect by becoming unemployed.

Participants' feelings of responsibility towards their circumstances and sense of feeling tarnished were strongly shaped by their mental health issues, which also led some participants to self-stigmatise. This meant that they tended to agree with public stereotypes towards unemployment and mental health and internalised these views, which exacerbated their low self-worth and feelings of demoralisation towards their circumstances (Corrigan \& Watson, 2002; Rü sch et al., 2006).

Participants' unemployment also created practical difficulties that placed a great deal of pressure on them. These difficulties related to feeling stigmatised and its associated problems of knowledge (ignorance or misinformation), attitudes (prejudice) and behaviour (discrimination) (Thornicroft et al., 2007). For example, participants felt a strong pressure from others to obtain work, simply by virtue 
of their status as university graduates who had degrees and should therefore be able to enter work without any difficulty. The invisibility of their disability meant they were often perceived by others as being lazy, which only served to add to the pressure that they felt.

While participants were generally quite sure that others would react negatively to their unemployment, they were unsure about the type of response that their mental health issues would receive, even from close friends and family. They therefore demonstrated a strong reluctance to disclose their mental health issues to others, especially in an employment context. Research suggests that people with mental health issues have to cope with widespread stigma and discrimination (Schomerus et al., 2012), and the dilemma of whether to disclose is a common problem for individuals with mental health issues (Wheat et al., 2010).

Disclosure of mental health issues in the workplace has been linked with the negative response of rejection or the positive response of social support; whereas non-disclosure carries the risk of discovery, which can be a continual source of stress (Brohan et al., 2014; Brohan et al., 2012; Link, Mirotznik, \& Cullen, 1991). Indeed a major concern for some participants was that their mental health issues were detectable merely from their outward appearance and behaviour. However, further research is needed to better understand the disclosure beliefs and behaviours of those with mental health issues (Brohan et al., 2012).

\section{Implications for Universities and Student Support}

While the small sample size and idiographic nature of IPA clearly circumscribes the ability to make generalised statements about the practical implications of this work, tentative claims, based on participants' experiences, have therefore been cautiously put forward for consideration.

There does seem to be a need to better manage students who have common mental health issues and their expectations of work and employment after graduation, which might be unrealistically high in some cases. Indeed participants' hopes and expectations for their lives after university were mostly based on the assumption that they would obtain suitable jobs almost immediately after university, which was unfortunately not the case. This study has demonstrated how closely their identity and high expectations as graduates were bound-up with their subsequent unemployment, which combined with a lack of access to work led to a deterioration in their mental health and reduced the opportunities for recovery.

Given how vulnerable these graduates were to unemployment, universities and their student support services (e.g., health, counselling, employment/careers, alumni associations, peer support groups) need to promote a greater awareness among their students with common mental health issues that the transition into employment is a turbulent and potentially dangerous time with numerous pitfalls. These services therefore have a vital role to play in helping these students to prepare for periods of unemployment, a prolonged job search and a series of 
survival-type jobs after they leave university.

As a further initiative, universities could also provide some (voluntary) workshops or seminars for final year students to help them prepare for life after university. An important part of this initiative would be to encourage former graduates-who have struggled and successfully overcome unemployment and mental health issues - to stay in touch with their university, so that a system of prospective buddying or mentoring could be established, perhaps coordinated through counselling services. These graduates could provide examples of their experiences (positive and negative), including the sources of support and means of coping that they had found helpful (and unhelpful) in maintaining a positive outlook. These workshops might also serve to better prepare students for a potential revision of their career aspirations, which in some cases may have to be revised downwards from their original ambitions prior to graduation.

\section{Acknowledgements}

Professor Mark Gabbay is part-funded by the National Institute for Health Applied Research Collaboration North West Coast (NIHR ARC NWC). The views expressed are those of the authors and not necessarily those of the NHS, the NIHR or the Department of Health and Social Care.

We would like to thank our study participants for giving their time to share their experiences with us.

\section{Conflicts of Interest}

The authors declare no conflicts of interest regarding the publication of this paper.

\section{References}

Bakke, E. W. (1940). Citizens without Work: A Study of the Effects of Unemployment upon the Workers' Social Relations and Practices. New Haven, CT: Yale University Press. https://doi.org/10.1525/9780520919242

Becker, G. (1997). Disrupted Lives: How People Create Meaning in a Chaotic World. Berkeley, CA: University of California Press.

Borgen, W. A., Hatch, W. E., \& Amundson, N. E. (1990). The Experience of Unemployment for University Graduates: An Exploratory Study. Journal of Employment Counseling, 27, 104-112. https://doi.org/10.1002/j.2161-1920.1990.tb00369.x

Brocki, J. J. M., \& Wearden, A. J. (2006). A Critical Evaluation of the Use of Interpretative Phenomenological Analysis (IPA) in Health Psychology. Psychology and Health, 21, 87-108. https://doi.org/10.1080/14768320500230185

Brohan, E., Evans-Lacko, S., Henderson, C., Murray, J., Slade, M., \& Thornicroft, G. (2014). Disclosure of a Mental Health Problem in the Employment Context: Qualitative Study of Beliefs and Experiences. Epidemiology and Psychiatric Sciences, 23, 289-300. https://doi.org/10.1017/S2045796013000310

Brohan, E., Henderson, C., Wheat, K., Malcolm, E., Clement, S., Barley, E. A., Slade, M., \& Thornicroft, G. (2012). Systematic Review of Beliefs, Behaviours and Influencing Factors Associated with Disclosure of a Mental Health Problem in the Workplace. BMC 
Psychiatry, 12, 11. https://doi.org/10.1186/1471-244X-12-11

Burke, R. J., \& Macdermid, G. (1999). A View of Their Economic Future: An Exploratory Study among Recent Business School Graduates. Education + Training, 4, 114-119. https://doi.org/10.1108/00400919910255898

Cassidy, T. (1994). The Psychological Health of Employed and Unemployed Recent Graduates as a Function of their Cognitive Appraisal and Coping. Counselling Psychology Quarterly, 7, 385-397. https://doi.org/10.1080/09515079408254161

Cassidy, T., \& Wright, L. (2008). Graduate Employment Status and Health: A Longitudinal Analysis of the Transition from Student. Social Psychology of Education, 11, 181191. https://doi.org/10.1007/s11218-007-9043-x

Corrigan, P. W., \& Watson, A. C. (2002). The Paradox of Self-Stigma and Mental Illness. Clinical Psychology: Science and Practice, 9, 35-53. https://doi.org/10.1093/clipsy.9.1.35

Dooley, D., Catalano, R., \& Brownell, A. (1986). The Relation of Economic Conditions, Social Support, and Life Events to Depression. Journal of Community Psychology, 14, 103-119. https://doi.org/10.1002/1520-6629(198604)14:2<103::AID-JCOP2290140202>3.0.CO;2-I

Erikson, E. H. (1980). Identity and the Life Cycle. London: Norton.

Feather, N. T., \& Bond, M. J. (1983). Time Structure and Purposeful Activity among Employed and Unemployed University Graduates. Journal of Occupational Psychology, 56, 241-254. https://doi.org/10.1111/j.2044-8325.1983.tb00131.x

Hayes, J., \& Nutman, P. (1981). Understanding the Unemployed: The Psychological Effects of Unemployment. London: Tavistock.

Hopson, B., \& Adams, J. (1976). Towards an Understanding of Transition: Defining Some Boundaries of Transition Dynamics. In J. Adams, J. Hayes, \& B. Hopson (Eds.), Transition: Understanding and Managing Personal Change (pp. 3-25). Montclair, NJ: Allanheld, Osmun \& Co.

Howe, N., \& Strauss, W. (2000). Millennials Rising: The Next Great Generation. New York: Vintage Books.

Institute of Student Employers \& Association of Graduate Careers Advisory Services (2020). Covid-19: The Impact of the Crisis on Student Recruitment and Development? London: Institute of Student Employers.

Institute of Student Employers (2020). Student Recruitment Survey 2020: Challenge and Resilience in the Year of Covid-19. Key Trends and Issues in Student Recruitment in the Recruitment Seasons 2019-20. London: Institute of Student Employers.

JISC \& Association of Graduate Careers Advisory Services (2020). What Do Graduates Do? Bristol: Jisc/AGCAS.

Kasl, S. V. (1982). Strategies of Research on Economic Instability and Health. Psychological Medicine, 12, 637-649. https://doi.org/10.1017/S0033291700055744

Lacković-Grgin, K., Milosavljević, B., Cvek-Sorić, I., Opačić, G., \& Deković, M. (1996). Social Support and Self-Esteem in Unemployed University Graduates. Adolescence, 31, 701-707.

Levinson, D. J. (1978). The Seasons of a Man's Life. New York: Ballantine Books.

Levinson, D. J. (1996). The Seasons of a Woman's Life. New York: Ballantine Books.

Link, B. G., Mirotznik, J., \& Cullen, F. T. (1991). The Effectiveness of Stigma Coping Orientations: Can Negative Consequences of Mental Illness Labeling Be Avoided? Journal of Health and Social Behavior, 32, 302-320. https://doi.org/10.2307/2136810

McKee-Ryan, F. M., Song, Z., Wanberg, C. R., \& Kinicki, A. J. (2005). Psychological and 
Physical Well-Being during Unemployment: A Meta-Analytic Study. Journal of Applied Psychology, 90, 53-76. https://doi.org/10.1037/0021-9010.90.1.53

McManus, S., Bebbington, P., Jenkins, R., \& Brugha, T. (2016). Mental Health and Wellbeing in England: Adult Psychiatric Morbidity Survey, 2014. Leeds: NHS Digital.

McManus, S., Meltzer, H., Brugha, T., Bebbington, P., \& Jenkins, R. (2009). Adult Psychiatric Morbidity in England, 2007: Results of a Household Survey. Leeds: NHS Information Centre.

National Institute of Health and Clinical Excellence (2011). Common Mental Health Disorders: Identification and Pathways to Care. NICE Clinical Guideline 123. London: NICE.

National Union of Students-Union of Students in Ireland. March (2017). NUS-USI Student Wellbeing Research Report, 2017. Belfast: NUS-USI Northern Ireland.

O'Connor, D. J., \& Wolfe, D. M. (1987). On Managing Midlife Transitions in Career and Family. Human Relations, 40, 799-816. https://doi.org/10.1177/001872678704001202

Olesen, S. C., Butterworth, P., Leach, L. S., Kelaher, M., \& Pirkis, J. (2013). Mental Health Affects Future Employment as Job Loss Affects Mental Health: Findings from a Longitudinal Population Study. BMC Psychiatry, 13, 1-9.

https://doi.org/10.1186/1471-244X-13-144

Paul, K. I., \& Moser, K. (2009). Unemployment Impairs Mental Health: Meta-Analyses. Journal of Vocational Behavior, 74, 264-282. https://doi.org/10.1016/j.jvb.2009.01.001

Pukey, W. W. (1970). Self-Concept and School Achievement. Upper Saddle River, NJ: Prentice-Hall.

Rusch, N., Hölzer, A., Hermann, C., Schramm, E., Jacob, G. A., Bohus, M., Lieb, K., \& Corrigan, P. W. (2006). Self-Stigma in Women with Borderline Personality Disorder and Women with Social Phobia. The Journal of Nervous and Mental Disease, 194, 766 773. https://doi.org/10.1097/01.nmd.0000239898.48701.dc

Schaufeli, W. B., \& Van Yperen, N. W. (1992). Unemployment and Psychological Distress among Graduates: A Longitudinal Study. Journal of Occupational and Organizational Psychology, 65, 291-305. https://doi.org/10.1111/j.2044-8325.1992.tb00506.x

Schomerus, G., Schwahn, C., Holzinger, A., Corrigan, P. W., Grabe, H. J., Carta, M. G., \& Angermeyer, M. C. (2012). Evolution of Public Attitudes about Mental Illness: A Systematic Review and Meta-Analysis. Acta Psychiatrica Scandinavica, 125, 440-452. https://doi.org/10.1111/j.1600-0447.2012.01826.x

Shiels, C., Gabbay, M., \& Exley, D. (2008). Psychological Distress in Students Registered at a University-Based General Practice. Primary Care \& Community Psychiatry, 13, 9-18.

Smith, J. A. (1996). Beyond the Divide between Cognition and Discourse: Using Interpretative Phenomenological Analysis in Health Psychology. Psychology \& Health, 11, 261-271. https://doi.org/10.1080/08870449608400256

Smith, J. A. (2004). Reflecting on the Development of Interpretative Phenomenological Analysis and Its Contribution to Qualitative Research in Psychology. Qualitative Research in Psychology, 1, 39-54.

Smith, J. A., Flowers, P., \& Larkin, M. (2009). Interpretative Phenomenological Analysis: Theory, Method and Research. London: Sage.

Smith, J. A., Flowers, P., \& Osborn, M. (1997). Interpretative Phenomenological Analysis and the Psychology of Health and Illness. In L. Yardley (Ed.), Material Discourses of Health and Illness (pp. 68-91). London: Routledge.

Thornicroft, G., Rose, D., Kassam, A., \& Sartorius, N. (2007). Stigma: Ignorance, Prejudice or Discrimination? The British Journal of Psychiatry, 190, 192-193. 
https://doi.org/10.1192/bjp.bp.106.025791

Twenge, J. M. (2006). Generation Me: Why Today's Young Americans Are More Confident, Assertive, Entitled and More Miserable than Ever Before. New York: Free Press.

Wheat, K., Brohan, E., Henderson, C., \& Thornicroft, G. (2010). How Should Doctors Advise People with Mental Illness Who are Seeking Work? Journal of the Royal Society of Medicine, 103, 83-86. https://doi.org/10.1258/jrsm.2009.090317 